\title{
Emerging Economies: Differences and Distances ${ }^{1}$
}

Pankaj Ghemawat, New York University Stern School of Business, USA, and IESE Business School, Spain

Steven A. Altman, New York University Stern School of Business, USA

\section{Introduction}

A full 78\% of AIB members are based in advanced economies, yet our research and teaching increasingly demand attention to emerging economies. Despite the recent emerging market slowdown, the IMF still projects these economies to deliver 72\% of global growth from 2015 to 2020 in purchasing power parity (PPP) terms (IMF World Economic Outlook Database, April 2016). In this short article, we delve beyond the obvious differences between emerging and advanced economies to present a more holistic characterization of these important—but often misunderstood - parts of the world.

We begin by examining the classification of economies based on levels of development, both to draw attention to the controversies involved as well as to clarify the basis for the material that follows. Then, we apply the CAGE distance framework (Ghemawat, 2001) to look systematically at differences and distances between advanced and emerging economies. The CAGE framework identifies four dimensions of distance (cultural, administrative/institutional, geographic, and economic), and we analyze these first with respect to internal (unilateral) characteristics of countries and then in reference to attributes that can only be measured bilaterally, e.g., common languages and geographic distance.
IMF's current World Economic Outlook states that their classification is "not based on strict criteria, economic or otherwise, and it has evolved over time." Nonetheless, it still seems to reflect criteria for advanced status listed in earlier editions: "per capita income levels well within the range indicated by the group of industrial countries, well-developed financial markets and high degrees of financial intermediation, and diversified economic structures with relatively large and rapidly growing service sectors" (IMF World Economic Outlook, May 1997).

Figure 1 compares lists of emerging economies and their analogues (low- and middle income, etc.) across commonly used classification systems. Given our own emphasis on multi-dimensional (CAGE) distance, we prefer the IMF's broader set of criteria to the narrow economic cutoffs used by the World Bank and UNDP. The World Bank defines low- and middle-income countries as those with purchasing power parity-adjusted GNI of less than $\$ 12,736,{ }^{2}$ thus excluding many oil-rich countries as well as several others, primarily in Latin America and the Caribbean. The UNDP uses their Human Development Index $(\mathrm{HDI})$, comprised of per capita income, educational attainment, and life expectancy, and classifies countries without "very high" HDI as those below 0.8 (United Nations Development Programme, 2015) (on a 0 to

\section{Classification Controversies}

Antoine van Agtmael coined the term "emerging markets" in 1981 to promote a Third World investment fund, but his definition seems to have evolved over time. In 2013, he declared the United States the next great emerging market (Zweig, 2013). Others ranging from McKinsey managing director Dominic Barton to Harvard professor Krishna Palepu have also ascribed, for different reasons, emerging economy characteristics to the U.S. However, stretching "emerging" to incorporate virtually all countries would also make it a contentless qualifier. We choose, therefore, to stick with earlier conceptions of emerging markets, and follow the IMF's classification of countries into "advanced" versus "emerging and developing."

Classifying countries based on levels of economic development is itself politically sensitive, and the
Figure 1: Venn Diagram Comparing Classifications of Emerging and Developing Countries

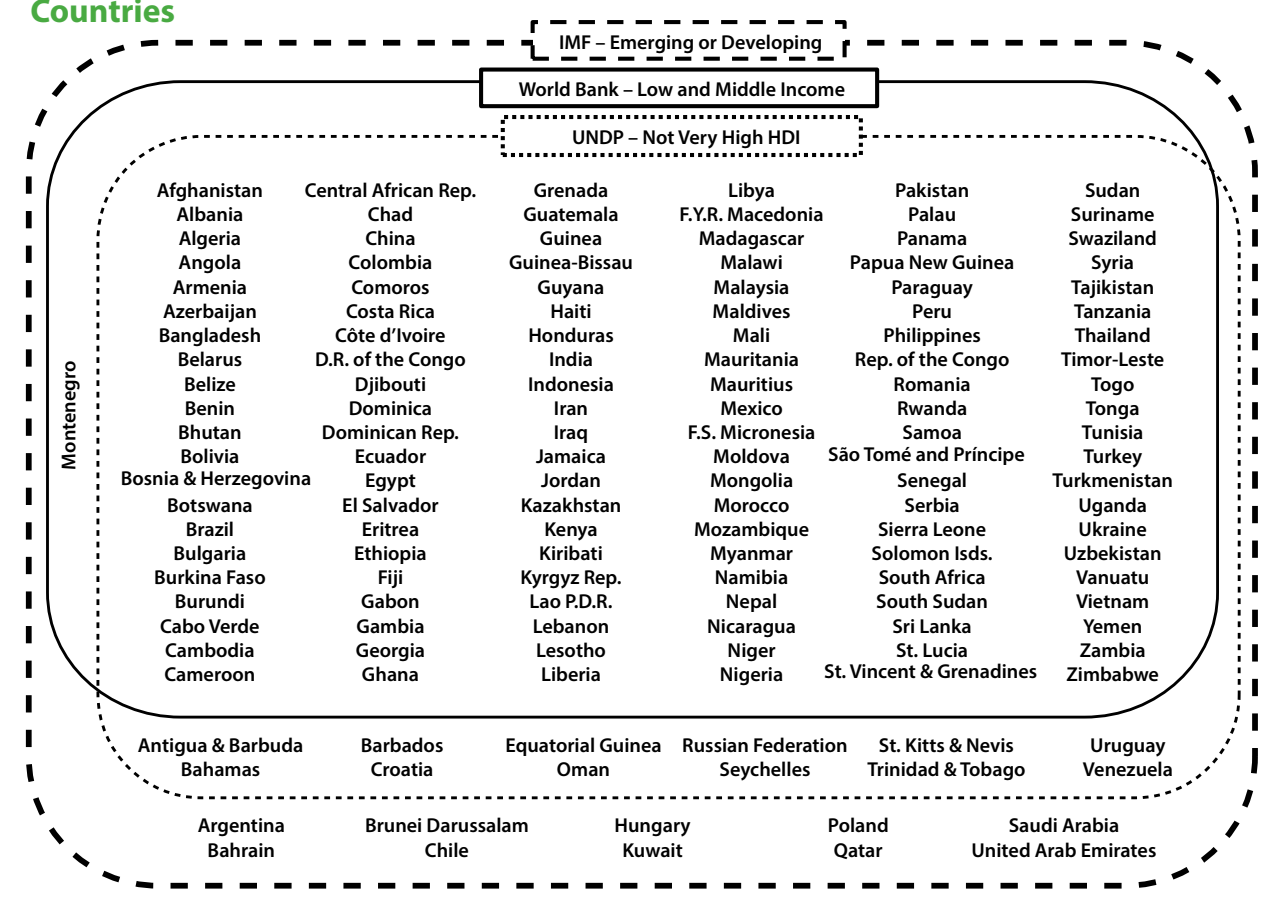

Sources: IMF, World Bank, United Nations Development Program (UNDP). 
1 scale), again excluding several oil-rich countries as well as Argentina, Chile, Hungary, and Poland.

Figure 2. Internal Differences between Advanced and Emerging Economies (Weighted by GDP)

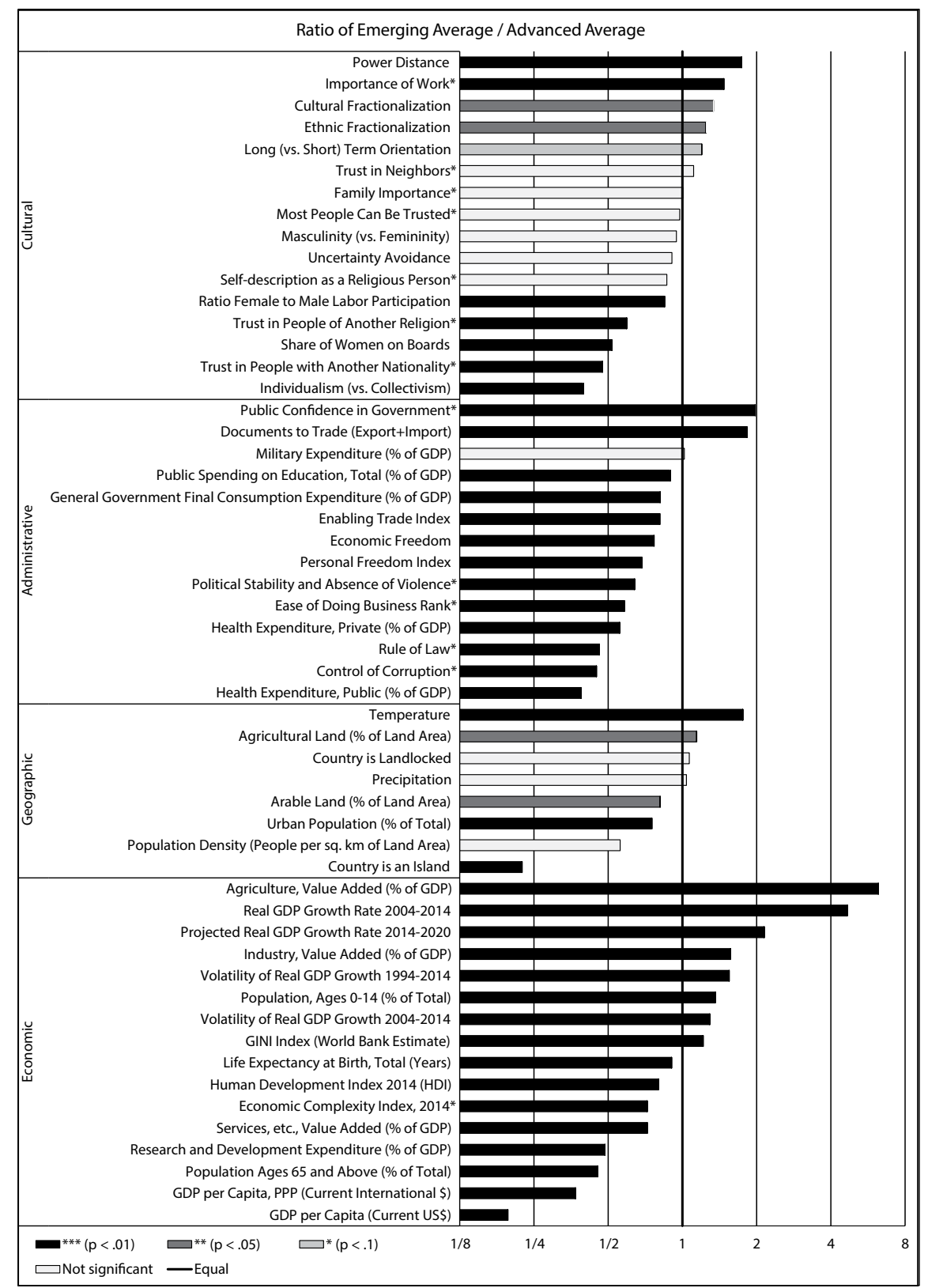

Notes: Variables marked with asterisk $\left(^{*}\right)$ were transformed using min-max normalization prior to calculating comparisons. ${ }^{5}$

Sources: World Values Survey (waves 2005-2009 and 2010-2014); Fearon, "Ethnic and cultural diversity by country," (2003); Geert Hofstede Dimension Data Matrix (2015); World Bank World Development Indicators (2016); World Bank Climate Change Knowledge Portal; Catalyst Knowledge Center (2014); GMI Ratings Women on Boards Survey (2013); World Bank Worldwide Governance Indicators (2014); Heritage Foundation Index of Economic Freedom (2015); World Economic Forum Global Enabling Trade Report (2014); World Bank Ease of Doing Business (2016); Centre d'Etudes Prospectives et d'Informations Internationales (CEPII) Geography Database; Google Maps; International Monetary Fund World Economic Outlook Database (October 2015), United Nations Development Program HDI (2015); Cato Institute, Fraser Institute and Friedrich Naumann Foundation for Freedom Human Freedom Index (2015); Ricardo Hausmann, César A. Hidalgo, et al. The Atlas of Economic Complexity: Mapping Paths to Prosperity. (Cambridge, MA.: Harvard's Center for International Development (CID); Harvard Kennedy School; MIT Media Lab, 2011), http://www.atlas.cid.harvard.edu/book/.

\section{What Is Different about Emerging Economies?}

While the IMF's classification scheme does consider a wider array of country characteristics than the alternatives discussed in the previous section, it still addresses only the economic dimension of the CAGE framework, and there are even some surprises on that dimension itself. Figure 2 covers country characteristics across all four CAGE dimensions. It compares GDP-weighted (rather than simple) averages to highlight differences that business practitioners encounter in the large markets on which they often focus. ${ }^{3}$

Starting with economic differences, the most obvious are the emerging economies' lower per capita incomes and faster real growth rates. But even those characterizations fail to apply to every emerging economy: the IMF lists both Qatar and Yemen as emerging or developing even though they had the world's third-highest GDP per capita and lowest real growth rate, respectively, in 2015. From a business perspective, lower R\&D intensity in emerging economies is particularly salient, given the association between R\&D (and advertising) intensity with resources that enable firms to become multinational. Also, the higher proportion of GDP coming from the industrial sector in emerging economies implies that it is no longer appropriate to treat "industrialized countries" and "advanced economies" as synonymous.

Culturally, there are statistically significant differences on three of Hofstede's dimensions of national culture (Hofstede, 1980; Hofstede \& Bond, 1988). Greater power distance, collectivism, and long-term orientation in emerging economies all imply requirements for executives to vary leadership practices. Based on data from the World Values Survey, people in emerging economies accord work a higher priority in their lives-presumably an advantage for employers-but have lower levels of trust in foreigners, which can complicate international business activities in particular. Furthermore, the higher cultural fractionalization and lower representation of women on boards in emerging economies highlight the importance of thinking about diversity within as well as across countries.

Administratively, emerging economies rank significantly worse than advanced economies on indicators of institutional quality, e.g., rule of law, political stability, and control of corruption, all of which can dampen international business activity. According to an estimate by Shang-Jin Wei $(2000$, p. 1), "an increase in the corruption level from that of Singapore to that of Mexico would have the same negative effect on inward FDI as raising the tax rate by fifty percentage points." Emerging economies also require more documents to conduct international trade and rank lower on the World Economic Forum's Enabling Trade 
Index. Surprisingly, despite their administrative weaknesses, publics in emerging economies express greater confidence in their governments.

Emerging economies also present distinct geographic conditions. They average lower levels of urbanization which impact both demand patterns and supply chains. Temperature levels are also higher, on average, in emerging economies. And while emerging economies' higher likelihood of being landlocked is not statistically significant, infrastructure deficiencies make landlocked emerging economies far less accessible than landlocked advanced economies.

The multifaceted differences between emerging and advanced economies hint at the limitations of previous efforts to characterize the salient differences among them in terms of one CAGE dimension-whether it be power distance (cultural), institutional voids (administrative), higher temperatures (geographic), or lower per capita incomes (economic) rather than more broadly. Previous characterizations are also limited by a focus on (an unduly narrow subset of) unilateral differences at the expense of bilateral (or multilateral) differences, even though the latter have been shown to have profound influences on international interactions (Ghemawat, 2017).

\section{What Is Distant (Bilaterally) about Emerging Economies?}

In addition to the distance created by differences in internal attributes, other sources of distance can only be assessed bilaterally across pairs of countries. Figure 3 provides a set of bilateral comparisons along the cultural, administrative, and geographic dimensions of the CAGE framework, incorporating variables on which gravity models have shown that

Figure 3. Bilateral Comparisons between Advanced and Emerging Economies (Weighted by GDP)

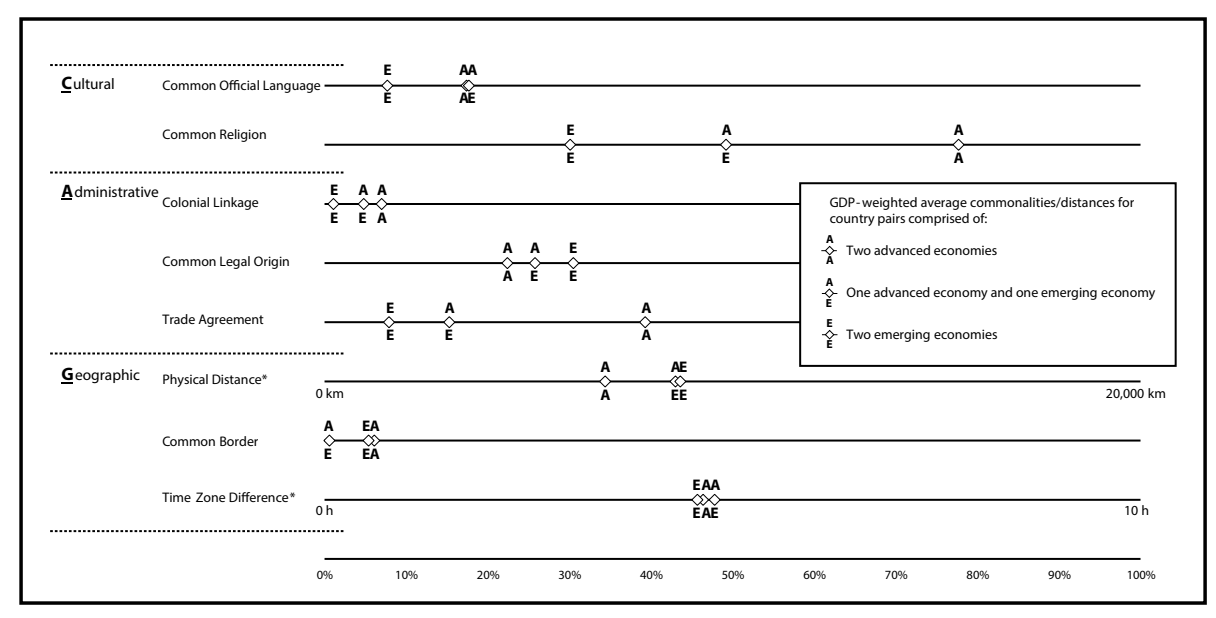

Notes: For variables marked with asterisk $\left({ }^{*}\right)$, distance rises from left-to-right across the chart; for all other variables, commonality/proximity rises from left-to-right. All differences (AA vs. AE, AE vs. EE, and AA vs. EE) are significant at the 0.01 level, except for Physical Distance (AE vs. EE) and Common Border (AA vs. EE) which are significant at the 0.05 level and Time Zone Differences (AA vs. AE and AA vs. EE) which are significant at the 0.1 level. The only difference that is not significant at any standard level is Common Official Language (AA vs. AE).

Sources: Based on data from Centre d'Etudes Prospectives et d'Informations Internationales (CEPII), Dow and Karunaratna (2006) (using series R1 and treating scores of 1-3 as reflecting a common religion), and World Trade Organization (WTO) greater distance significantly dampens trade and/or FDI. ${ }^{4}$ It compares commonalities and distances across pairs of two advanced economies, of one advanced economy and one emerging economy, and of two emerging economies. Here, we utilize sums of country pairs' GDPs as weights to compute weighted averages for each of the categories.

It is useful to consider the material summarized in Figure 3 separately from the perspectives of firms based in advanced and emerging economies. For a typical firm from an advanced economy, emerging economies are more different or distant - to a statistically significant extentthan other advanced economies on every variable except language and legal origins. Geographically, emerging economies are more than one-quarter more distant, and administratively, advanced economies are about two-and-a-half times as likely to have trade agreements with other advanced economies as with emerging economies. Based on a gravity model with the measures shown in the figure as explanatory variables (along with origin and destination country GDPs and fixed effects), shifting from the weighted average distance between two advanced economies to the weighted average distance between one advanced and one emerging economy is expected to reduce merchandise trade by $36 \%$ and FDI stocks by $29 \%$ ! Incremental distance, thus, clearly imposes substantial challenges on firms from advanced economies pursuing growth in emerging markets.

For firms expanding abroad from emerging economies, while similar levels of development create economic proximity with other emerging economies, many of the other commonalities that bind advanced economies together are absent. Emerging economies share common languages, common religions, colonial linkages, and trade agreements more often with advanced economies than they do among each other. The paucity of trade agreements between emerging economies is particularly striking: two emerging economies are half as likely as a pair comprised of one advanced and one emerging and one-fifth as likely as two advanced economies to have a trade agreement. The only variable where emerging economies benefit from the greatest commonalities with other countries is legal origins, a legacy of shared colonial histories.

Considering all of the variables in Figure 3 together, the gravity model indicates that firms from emerging economies face greater resistance due to non-economic distance when trading and investing in other emerging economies than they do in advanced economies: shifting from two emerging economies to one emerging and one advanced is expected to boost both trade and FDI by 15\% as a result of greater non-economic distances, on average, between emerging economies. And, of course, firms from emerging economies face far greater distance-related challenges in advanced economies than do competitors from advanced economies-many factors that make emerging 
economies harder for advanced economy based firms also apply in the reverse direction. These results imply that distance imposes even greater challenges on multinationals from emerging economies than on those from advanced economies, and our preliminary research also suggests that emerging market based multinationals also have weaker capabilities for traversing distance.

The greater distances faced by emerging economies as well as some of the unilateral characteristics covered in the previous section contribute to another barrier to business into and out of emerging economies: their lower levels of globalization as measured on our DHL Global Connectedness Index (Ghemawat \& Altman, 2016). Advanced and emerging economies are roughly at parity with respect to trade intensity-exports and imports of goods and services as a share of GDP. However, with respect to capital and people flows, advanced economies are four to five times as deeply globalized and advanced economies are nine times as deeply globalized with respect to international information flows.

\section{Conclusion}

The salient differences between advanced and emerging economies for multinational firms extend well beyond obvious ones such as lower income levels and faster growth. By applying the CAGE distance framework to analyzing them, we have sought both to provide a convenient sketch of many relevant differences as well as to illustrate the power of attention to multiple dimensions of distance when analyzing countries and strategies that seek to create value by doing business across them.

We contend that future research on emerging markets and multinationals based in them would benefit from greater attention to distance across multiple dimensions and to heterogeneity across countries and firms in their capacities for bridging distance. As firms stretch to traverse the great distances between advanced and emerging economies, research on them can also stretch our understanding more generally of distance effects and what enables some firms to handle more distance than others.

\section{References}

Dow, D., \& Karunaratna, A. 2006. Developing a multidimensional instrument to measure psychic distance stimuli. Journal of International Business Studies, 37(5): 578-602.

Ghemawat, P. 2001. Distance Still Matters: The Hard Reality of Global Expansion. Harvard Business Review, 79(8): 137-147.

Ghemawat, P. 2017. The Laws of Globalization. Cambridge: Cambridge University Press.

Ghemawat, P., \& Altman, S. A. 2016. DHL Global Connectedness Index 2016: The State of Globalization in an Age of Ambiguity. Retrieved from www.dhl.com/gci

Hofstede, G. 1980. Culture's consequences: international differences in work-related values (vol. 5). Beverly Hills, CA: Sage Publications.
Hofstede, G., \& Bond, M. H. 1988. The Confucius connection: From cultural roots to economic growth. Organizational Dynamics, 16(4): 5-21.

International Monetary Fund. May 1997. Washington, DC: World Economic Outlook.

International Monetary Fund. April 2016. Washington, DC: World Economic Outlook.

Nielsen, L. 2011. Classifications of countries based on their level of development: How it is done and how it could be done. IMF Working Papers, 1-45.

United Nations Development Programme. 2015. Human Development Report 2015. New York: United Nations.

Wei, S.-J. 2000. How taxing is corruption on international investors? Review of Economics and Statistics, 82(1): 1-11.

Zweig, J. 2013. Here Comes the Next Hot Emerging Market: the U.S. The Wall Street Journal, April 24.

\section{Endnotes}

1 This article is based in part on Chapter 11 of Pankaj Ghemawat, The Laws of Globalization and Business Applications, Cambridge University Press, 2017.

2 More specifically, for the 2016 fiscal year, high-income economies are those that had a gross national income per capita of $\$ 12,736$ or more in 2014, as reported at http://data.worldbank.org/about/country-and-lending-groups.

3 Analysis based on simple averages is more strongly affected by small economies that receive less attention from multinational firms. Nevertheless, there is a 0.9 correlation between weighted and unweighted versions of this analysis and in most cases, ratios that were greater than one in the weighted version were also greater than one in the simple averages version (and vice versa).

4 In a gravity model of merchandise exports, all of the variables shown in the figure were significant at the 0.01 level with expected signs except common legal origin which was significant at the 0.05 level. In a gravity model of FDI outward stocks, they were all significant at the 0.01 level except common religion, time zone difference, trade agreement, and common border which retained their expected signs but were not significant at any standard level.

5 Min-max normalization rescaled values to lie between 0 and 1 without changing the shapes of the relevant distributions. Variables from World Governance Indicators and Economic Complexity Index were normalized to avoid incorporating negative values into the ratio calculations; variables from World Values Survey were coded based on answers to individual survey questions and made comparable via normalization; World Bank's Ease of Doing Business ranks were normalized in order to reverse order and improve comparability with other data components.

Pankaj Ghemawat (pghemawa@stern.nyu.edu) is Global Professor of Management and Strategy and Director of the Center for the Globalization of Education and Management at the Stern School of Business at New York University, and the Anselmo Rubiralta Professor of Global Strategy at IESE Business School. He is a fellow of the Academy of International Business and the Strategic Management Society, and winner of the Academy of Management International Management Division's Booz Eminent Scholar Award.

Steven A. Altman (saltman@stern.nyu.edu) is Senior Research Scholar and Executive Director of the Center for the Globalization of Education and Management at the Stern School of Business at New York University. Prior to entering academia, he worked as a management consultant assisting clients with international and emerging market strategies across several industries and regions. 